\title{
Spletno nasilje, virtualno nasilje ali nasilje, ki uporablja nove tehnologije?
}

\author{
Maja Vreča
}

\section{So mladi res $\gg$ digitalni domorodci $\ll$ ?}

V

rstniško nadlegovanje in nasilje sta bila vedno sestavna dela odraščanja otrok in mladih, pa najsi gre za fizično nasilje ali pa nasilje, ki uporablja bolj prefinjene oblike, od verbalnega nasilja do obrekovanja in izločanja posameznikov. $\mathrm{V}$ zadnjih letih pa se je nasilje med mladimi korenito spremenilo. Otroci in mladostniki so čedalje bolj nadzorovani v svoji fizični realnosti in vsako zaznano nasilje običajno naleti na takojšnji odziv. Po drugi strani pa imajo mladi celo našo podporo pri selitvi v »virtualni« svet. Sporočamo jim, da so »digitalni domorodci $\ll$, ki jim je bil ta svet položen že v zibko, medtem ko bomo mi vedno le »imigranti« v svetu, ki nam bo do določene mere vedno ostal tuj. Vsekakor drži, da je naše globje razumevanje uporabe novih tehnologij, njihovega delovanja in vpliva na naše življenje in na družbo kot celoto zelo pomanjkljivo. A iz tega sklepati, da mladi s tem, ko so se rodili v ta svet, razumejo vse tisto, česar mi, z vsemi našimi izkušnjami, ne razumemo, je zelo naivno.

V Safe.si ugotavljamo, da so mladi v splošnem (omejeno) digitalno pismeni in medijsko bolj ali manj nepismeni (Center za varnejši internet, 20I8). To seveda velja za tiste otroke in mladostnike, ki so prepuščeni temu, da črpajo svoje poznavanje digitalnega sveta iz novih medijev in iz komunikacije z vrstniki.

Eden izmed pomembnih problemov mladih je, da pri težavah, na katere naletijo pri srečevanju s tehnologijami, pogosto ne vedo, na koga bi se obrnili. Niti mi niti oni se pogosto ne zavedamo, da so tudi na internetu 
ključnega pomena življenjske izkušnje, ki pa jih otroci še nimajo. Odrasli smo torej tisti, ki se moramo naučiti specifik interneta in novih tehnologij, da bomo lahko otrokom v oporo, če zaidejo v težave.

$S$ tem, ko odrasli mladim sporočamo, da so v tem »novem svetu « sami, jim sporočamo tudi, da je to pravzaprav nekakšen »divji zahod «, kjer velja zakon močnejšega in kamor ne seže roka pravice. $V$ pogovorih z mladimi, iz prijav in delavnic strokovnjaki Centra za varnejši internet opažamo, da mladi odraslih, z redkimi izjemami, ne vidijo v vlogi odraslih, ko gre za njihove probleme $\mathrm{v} \gg$ virtualnem « svetu. Vidijo nas kot generacije, ki jih je na ključnih področjih povozil čas. Opazijo predvsem, da nismo intuitivni pri rabi tehnologij, mi pa se običajno ne zavedamo, kako zelo slabo so otroci opremljeni za vstop v svet digitalnih tehnologij, saj se tudi nam običajno zdi, da je hitro in spretno $\gg$ klikanje « tudi znak poznavanja medija. V predinternetnih časih so bili odrasli za otroka referenca na vseh področjih, zdaj pa so na področju interneta in novih tehnologij to običajno kar njihovi vrstniki.

Sedanji mladi uporabniki so zrasli z vseprisotno novo tehnologijo, ki se jim zdi povsem samoumevna, zato so pri uporabi tehnologij samozavestni, saj so jim domače in tudi s stalnimi spremembami nimajo težav. Pri vsem tem navidezno ekspertnem znanju pa običajno spregledajo bistveno. Tisto, kar poznajo, temelji na podstati, ki je pravzaprav ne razumejo. Izkaže se, da večina mladih uporabnikov izredno slabo pozna delovanje in naravo omrežij ter tehnologij. Pomembno jim je le to, da njihove priljubljene aplikacije, igrice ali družbena omrežja delujejo - kako in zakaj, pa jih običajno ne zanima. To znanje se mogoče na prvi pogled zdi povsem nepotrebno, a zaradi svojega nepoznavanja so lahko idealne žrtve zavajanja in manipulacij.

Mladim je izredno pomembna njihova »digitalna podoba «. Ure in ure vložijo v pripravo tistega dela njihovega »digitalnega vtisa «, ki se ga zavedajo. Ob tem pa hkrati gradijo tudi veliko večji in njim nevidni $\gg$ digitalni odtis «. Odtis, ki prispeva h gradnji »big data « oziroma velikih podatkovnih baz, ki, če jim to dopustimo, prek naše rabe brskalnikov, družbenih omrežij, »brezplačniške « elektronske pošte, pa raznih aplikacij in igric ter celo preko vzorca naše uporabe računalniške miške beležijo bolj ali manj vse o nas - od naše dnevne rutine do naših najintimnejših želja in celo zdravstvenega stanja.

Pri iskanju po spletu se mladi tudi ne zavedajo, da vsi živimo v $\gg$ internetnem mehurčku «, ki nam zadetke iskanja razvršča glede na naše prejšnje izbire, kar pomeni, da nam iskalni niz med prvimi zadetki prikaže le tisto, za kar algoritmi $\gg$ mislijo «, da nas bo najbolj pritegnilo. Razvrstitev rezultatov je seveda izredno pomembna, saj povprečen uporabnik nikoli 
ne pogleda več kot prvih pet rezultatov iskanja, $95 \%$ uporabnikov tudi ne pogleda druge strani rezultatov.

Ko gre za medijsko pismenost pri preverjanju kredibilnosti virov, so mladi pogosto bistveno manj podkovani, kot si radi predstavljamo. Načelno sicer vedo, da ni nujno vse čisto res, kar je na internetu, a niti ne pomislijo, da bi preverili verodostojnost $\gg$ zanimivosti $\ll$, ki so jo dobili od prijatelja.

Tudi v družbenih omrežjih so objave, ki jih vidimo, povsem >personalizirane «; z uporabo majhnih zaprtih skupin, ki so trend med mladimi, pa se ta izolacija še stopnjuje. Tako na primer pristaši teorij zarot čez čas pri kateremkoli iskanju na vrhu dobijo le zadetke, ki potrjujejo teorijo zarote, v katero verjamejo. Isto velja za ekstremiste, kar v določeni meri pojasnjuje hitrost širjenja ekstremizmov, ki so jim mladi podvrženi še bolj kot odrasli z izdelanim pogledom na svet. Če se otrok vsega tega ne zaveda, si seveda težko ustvari neko realno sliko sveta, po katerem se navidezno giblje ( $>$ surfa $\ll$ ).

Morda se sliši nenavadno, a kljub temu, da otroci in mladi izpostavljajo svojo digitalno podobo kot nekaj izredno pomembnega, pogosto opažamo, da mladi svojih aktivnosti v »virtualnem svetu « ne jemljejo čisto resno. Odgovor $\gg$ saj mu nisem tega zares rekel, samo napisal sem mu« je nekaj povsem običajnega. To zlahka vodi tudi v nehoteno nasilje med vrstniki.

\section{Razni vidiki »virtualnega« nasilja}

Kombinacija družbenih omrežij, aplikacij za komuniciranje in pametnih telefonov je otrokom in mladim prinesla povsem drugačno pojmovanje zasebnosti, kot so ga imele generacije pred njimi. Mladi so spodbujani, da postanejo udeleženci v nekakšnem 24-urnemu »resničnostnemu šovu《. Večja, kot je tvoja »on-line« prisotnost, večje so tvoje možnosti, da boš res popularen med vrstniki. Pri tem že dolgo ni več najbolj pomembna kvaliteta objav, ampak štejejo predvsem količina in pogostost objav ter tisto najpomembnejše - število sledilcev.

Sledilci so tisti, ki s svojimi izbirami krojijo usodo spletnih podob mnogih mladih in odpirajo široko polje možnih zlorab. Mladi, ki se odločijo, da bodo sledili trenutnim modnim trendom in gradili svojo podobo spletnega vplivneža (angl. influencer), se morajo odzivati na želje in zahteve svojega občinstva, kar pomeni, da morajo objavljati veliko in se v veliki meri odreči svoji zasebnosti.

Pri tem so lahko izpostavljeni tudi temu, da postanejo lahka tarča spletnih nadlegovalcev ali »trolov«. Nekateri mladi in tudi malo manj mladi svoje frustracije sproščajo na spletu in postanejo $\gg$ troli $\ll$. Običajno 
so skriti za vzdevki in nadlegujejo druge uporabnike spleta z žaljivimi komentarji, izzivajo konflikte, provocirajo in uživajo v odzivih svojih žrtev. Mnogi otroci in mladi, ki jih je pritegnila možnost enostavnega objavljanja vsebin, so posledično doživeli zelo boleče napade, pogosto s strani popolnih neznancev. $\mathrm{V}$ času, ko so vsi mladi sistematično spodbujani $\mathrm{k}$ objavam, ki jih naredijo bolj ranljive in razgaljajo tudi njihovo zasebnost, so zlasti dekleta pogosto izpostavljena različnim napadom in žaljivim komentarjem o videzu, ki je v času odraščanja izredno pomemben.

Možnost uporabe vzdevkov olajša tudi nadlegovanje $\mathrm{z}$ »anonimkami«. Nadlegovalec žrtvi zlahka pošilja neprijetne ali preoblikovane fotografije in posnetke, grožnje ali druge strašljive vsebine. Lahko jo celo izsiljuje.

Žrtve takih nadlegovalcev so pogosto hudo prestrašene in običajno si ne upajo staršem ali učiteljem povedati, kaj se jim dogaja, saj jim »trol « grozi z maščevanjem, če si bo otrok drznil ukrepati. Posledice za žrtev so lahko hude. Pri nas sicer na srečo še nismo imeli zabeleženega primera mladostniškega samomora, ki bi bil posledica »virtualnega« nasilja, a v mnogih državah redno beležijo primere nadlegovanj in tudi samomorov med mladimi (Cook, 2019; Spletni viri G-K).

$\mathrm{Na}$ nove medije so se preselile tudi »tradicionalne« oblike nadlegovanja in nasilja. Zaprte skupine v družbenih omrežjih in aplikacijah za komuniciranje celo olajšajo izločanje iz skupin, širjenje govoric in podobno.

Družbeni mediji omogočajo tudi enostavno ustvarjanje lažnih profilov vrstnikov ali učiteljev ali pa ustvarjanje t. i. sovražnih (angl. hate) profilov, ki so v prvi vrsti namenjeni žaljenju in poniževanju posameznikov ali skupin. Ti profili so pogosto zelo okrutni.

Potem je tu še pošiljanje »ena na ena«. Mladi zelo radi uporabljajo aplikacije, ki omogočajo pošiljanje posnetkov preko pametnih telefonov. Pri tem imajo občutek, da gre za povsem zasebno komunikacijo. $\mathrm{Ne}$ zavedajo se, da pri tem uporabljajo komunikacijo, ki steče čez vrsto strežnikov, in ne vedo, da se ti posnetki na določenih strežnikih tudi hranijo. Ker so pametni telefoni zmogljivi fotoaparati, omogočajo tudi snemanje intimnih slik in posnetkov, ki so običajno namenjeni le končnemu naslovniku. Mladi te posnetke imenujejo »nudes «, v uporabi pa je tudi izraz »sexting « ali slovensko »sekstanje «. Gre za dokaj razširjen pojav, kjer predvsem dekleta pod pritiskom okolja svoje bolj ali manj razgaljene posnetke iz kopalnice pošiljajo fantu, ki ga želijo na ta način pritegniti, ali pa svojemu fantu, kot obliko intimne komunikacije. To počnejo tudi fantje, a v nekoliko manjši meri kot dekleta. Žal pa se občasno zgodi, da taki posnetki zaidejo tudi med širše občinstvo - pogosto tudi kot 
posledica izsiljevanja: »Če ne boš naredila ..., bom objavil slike, ki si mi jih poslala.«

Mladi neredko zaidejo v konflikte z vrstniki zgolj zaradi nepoznavanja »netikete « oziroma spletnega bontona. Na spletu, ravno tako kot $\mathrm{v}$ našem fizičnem svetu, obstaja vrsta nenapisanih pravil, ki se jih drži večina uporabnikov. Otrok pa običajno niti v svoji družini niti v šoli ne dobi napotkov, kaj velja za lepe manire na spletu - ali vsaj tega, kaj so osnovna pravila dopustnega obnašanja.

Eden od najpogostejših razlogov za tovrstne spore je objavljanje slik ali videoposnetkov, na katerih so prijatelji ali sošolci, brez njihovega pristanka. Otroci - žal pa tudi mnogi odrasli - se namreč ne zavedajo, da se tu internet korenito loči od našega fizičnega sveta. Če pokažejo prijateljem slike s počitnic ali z zabave, te slike vidi le ozek krog ljudi in tudi ti so jih le enkrat videli in kasneje večino tudi pozabili. Če pa iste slike objavijo na internetu, je to vidno veliko širšemu krogu ljudi oziroma verjetno kar vsemu svetu, saj velik del otrok - žal tudi odraslih - ne zna nastaviti zaščite zasebnosti svojih objav v spletnem orodju, ki ga uporabljajo. Kar je objavljeno, ostane na spletu. Tudi pri izbrisani povezavi do slike je ta še vedno dostopna na strežniku družbenega omrežja. Pri objavah »zelo zanimivih « slik se zelo hitro zgodi, da se širijo in množijo s skorajda svetlobno hitrostjo. Take objave so lahko stvar ponesrečene šale, nepremišljenosti ali tudi zlonamernosti.

Omeniti velja, da so lahko celo otrokovi starši tisti, ki z nepremišljenimi objavami spravijo svojega otroka v položaj žrtve. Novi starši so seveda zelo srečni in mnogi želijo z drugimi deliti vsak otrokov trenutek. Objavijo slike s pripisi »kako je ljubek, ko se kremži《 ali pa »prvič na kahlici«. Nekaj let kasneje se osnovnošolec, ko njegovi sošolci najdejo »ljubke« slike staršev in jih delijo z drugimi, lahko počuti zelo slabo. V oviru aktivnosti projekta Safe.si in v okviru osveščevalnih aktivnosti Arnesa veliko govorimo s šolami, ki nam poročajo, da je najbolj pogost pojav, ki ga zaznavajo $\mathrm{v}$ zadnjih letih, predvsem nedovoljeno snemanje in objava posnetkov. Tu gre lahko za posnetke učiteljev, običajno pri pouku, ali vrstnikov, ki jih zelo pogosto posnamejo $\mathrm{v}$ neprijetnih situacijah in posnetke lahko dodatno obdelajo. Na voljo so celo že pripravljena orodja za popačenje slike, kot je npr. risanje rogov. Take objave so lahko mišljene tudi kot šala, a običajno jih tisti, ki je na posnetku, ne vidi tako.

Žal tudi opažamo, da so mladi, ki so priče nadlegovanju, pogosto le pasivni opazovalci. Ni neobičajno, da se prav nihče ne postavi na stran žrtve. Pogosto namreč tudi otroci, ki dogajanje spremljajo, le-tega ne prepoznajo kot nasilje. Neredko je taka tudi reakcija staršev, predvsem staršev storilcev: »Pa saj so še otroci - se pač igrajo, a ne?« 


\section{Šola in $\gg$ virtualno $\ll$ nasilje}

Šole k izzivom spletnega nasilja pristopajo različno. Iz odzivov udeležencev na predavanjih in delavnicah je razvidno, da na nekaterih šolah nasilje med njihovimi učenci, ki se ne dogaja $v$ razredu, še vedno obravnavajo kot nekaj, kar ni stvar šole. Obravnavo fizičnega nasilja imajo šole običajno dobro določeno $v$ svojih pravilnikih, ki ji tudi uporabijo pri odzivanju na pojave fizičnega nasilja $v$ šoli.

Ko se nasilje preseli na splet, ga v marsikateri šoli ne obravnavajo več kot del šolske problematike, kar se izkazuje za slab pristop. Spletno nasilje ima namreč pogosto zelo neprijeten povratni učinek (angl. »ping-pong « efekt). Običajno se začne v fizičnem svetu, se nadaljuje in razmahne $\mathrm{v}$ »virtualnem « in se potem spet vrne v fizičnega $\mathrm{v}$ veliko hujši obliki.

Na srečo strokovnjaki na Arnesu opažamo, da se ta perspektiva počasi spreminja. Vse več šol se aktivno vključuje v dogajanje, ko zaznajo, da se dogaja »nevidno « nasilje, in vse redkejše so tiste šole, ki na to gledajo kot na problem, ki se ne tiče šole, če se ni zgodil ravno med šolsko uro ali v šolskem prostoru. Naše dosedanje izkušnje kažejo, da je na šolah, ki hitro rešujejo vsak pojav nasilja, le-tega manj in je tudi manj intenzivno. Ažurno in jasno odzivanje na nasilje zmanjšuje pojavnost nasilja in deluje preventivno.

$S$ problematiko spletnega nasilja se mnoge šole uspešno soočajo. $O$ tem pričajo primeri dobrih praks, kot je na primer priprava internih aktov, ki jih šole pripravijo skupaj s starši. Če ti pravilniki vključujejo načrtovanje proaktivnih in preventivnih dejavnosti s področja spletne varnosti in rabe pametnih telefonov ter nabor možnih ukrepov ob kršitvah, se starši storilcev in žrtev, zaradi vključenosti v pripravo šolskih pravil, od kršitvah drugače odzovejo.

Za odzivanje na nasilje sicer ne obstaja splošen pristop (»recept «), ki bi deloval $\mathrm{v}$ vseh primerih. Na ustreznost odziva vplivajo mnogi dejavniki, od starosti in spola žrtve ter oblike nasilja do specifik lokalnega okolja in tudi staršev žrtev in storilcev.

Obstaja pa nekaj splošnih predpostavk za uspešno omejevanje »virtualnega « nasilja na šolah. Sodelovanje staršev pri pripravi šolskih pravil smo že omenili. Verjetno pa je najbolj pomembna aktivnost ozaveščanje - tako učencev, kot učiteljev in staršev. Pogosto se namreč otroci, ki nasilje izvajajo ali pri njem sodelujejo, niti ne zavedajo teže lastnega početja in se jim zdi, da gre le za šalo. Drugi problem »oddaljenega « nasilja je odsotnost povratne informacije o tem, kako hudo je žrtev prizadeta. Zaradi tega nasilnež pogosto izvede veliko hujše nasilje, kot bi ga, če bi 
imel svojo žrtev pred seboj. Šola je tista, ki lahko učence in učitelje nauči prepoznavati spletno nasilje, in tista, ki se mora vključiti v njegovo aktivno reševanje, ko se pojavi. Šole poročajo, da so najbolj uspešne, če kombinirajo gostovanja zunanjih izvajalcev predavanj in delavnic ter redne aktivnosti, ki jih vključujejo v pedagoški proces. Običajno imajo predavanja in delavnice, ki jih izvajajo zunanji strokovnjaki, večjo težo pri poslušalcih, a če temu ne sledijo tudi kasnejše aktivnosti na šoli, postane tematika zlahka pozabljena.

Zakaj je osveščanje tako pomembno in ga vedno izpostavljamo na prvem mestu? Običajno storilec, ki izvaja nasilje, to lahko počne, ker njegovi vrstniki dogajanje molče spremljajo in se na nasilje ne odzovejo. Najbolj običajen odgovor na vprašanje: »Zakaj nisi nikomur povedal, kaj se dogaja? « je: »Nočem tožarit.《 Če torej otroci, ki so priče nasilja, to prepoznajo kot nasilje in so ponotranjili sporočilo, da se je treba na nasilje odzvati in pomagati žrtvi, namesto da s svojim molkom ščitijo storilca - da je žrtev tista, ki potrebuje pomoč, in ne nasilnež -, ne bomo imeli težav z odkrivanjem storilcev in s preprečevanjem nadaljnjih incidentov.

Pogosto se tudi dogaja, da se žrtve nasilja s svojim problemom sicer obrnejo na učitelja ali svetovalnega delavca na šoli, a hkrati prosijo, naj tega nikomur ne pove, saj se bojijo, da se bo njihov položaj še poslabšal.

Šola mora otrokom posredovati nedvoumno sporočilo, da je nasilje nedopustno in da bo vedno ukrepala pri tem. Hkrati jim mora sporočati, da zna zaščititi tako žrtev, kot tistega, ki bo žrtvi pomagal, in da se zna tudi odzvati na dogajanje. Zelo pomembno je, da se žrtev zaveda, da ustrahovalci nimajo pravice početi tega, kar počnejo, ter da ima nekoga, na katerega se lahko obrne po pomoč.

Pri odzivnosti šol na »virtualno《 nasilje se srečujemo še z dvema ključnima izzivoma. Šole nimajo vedno dovolj znanja in ustreznih kadrov, ki bi tematiko poznali do te mere, da bi vedeli, kako se odzvati na posamezno obliko nasilja. Drugi izziv je strah pred tehnologijo. Mnogo zaposlenih v šolstvu se ob srečanju s pojavi in oblikami nasilja, ki jih ne poznajo in ne razumejo, raje sploh ne odzove nanje, saj imajo občutek, da bodo ob odzivu pokazali svoje nepoznavanje tehnologij. Njihovo sporočilo storilcem in žrtvam nasilja ne bi moglo biti slabše. Šole o opisanem poročajo strokovnjakom najpogosteje ustno $\mathrm{v}$ zaupnem okolju delavnic. Negativna posledica neodziva ali zanikanja problema na šoli je zato tudi pomanjkanje širjenja zanesljivih informacij o nasilnih dogodkih z dokumentiranimi objavami, ki bi omogočale sistematičen razvoj ukrepov za pomoč. 


\section{Glavni akterji in projekti, ki naslavljajo problem} »virtualnega « nasilja

V Sloveniji se s pojavi spletnega nasilja srečujemo že zelo dolgo. Na Arnesu (Akademska in raziskovalna mreža Slovenije) smo se z njim prvič srečali leta 1995, ko smo omogočili dostop do interneta učencem in dijakom, ki pa so hitro odkrili široke možnosti uporabe in zlorabe novih platform. $\mathrm{Na}$ Arnesu smo bili že v prvem letu prisiljeni odkrivati pristope za odzivanje na nasilje in snovati ukrepe za njegovo preprečevanje. V letu I999 je bil Arnes kot pridruženi član povabljen v evropski projekt DOT.SAFE, ki se je ukvarjal z zaščito otrok in mladostnikov na spletu. Ko se je Slovenija v letu 2004 pridružila Evropski uniji, smo se lahko na področju varne rabe spleta mladih pridružili evropskemu združenju Insafe in ustanovljen je bil nacionalni projekt Safe.si. Arnes je bil ustanovni član in je ves ta čas ostal eden od ključnih deležnikov v projektu. Vzporedno Arnes izvaja samostojne aktivnosti, ki niso neposredno vezane na projekt, a so z njim v sinergiji. Trenutno je v ospredju množični brezplačni spletni tečaj varne rabe interneta in naprav (MOST-V oziroma MOOC-V), ki naslavlja širok nabor tematik, od tehničnih vidikov, varovanja zasebnosti in medijske pismenosti do tematik zasvojenosti in nasilja. Tečaj je zasnovan tako, da v celoti pokriva področje varnosti, kot ga določa evropski kompetenčni model DIGCOMP in ga Ministrstvo za izobraževanje, znanost in šport priznava kot dopolnilno izobraževanje učiteljev. Tečaj dvakrat letno poteka že pet let, od leta 2014, in je v prvi vrsti namenjen zaposlenim v šolstvu. V prvih desetih izvedbah se je vanj vključilo 7800 udeležencev; uspešno ga je zaključilo $65 \%$ udeleženih. V letu 2019 je Arnes pripravil tudi tečaj o varni rabi interneta in naprav za učence druge in tretje triade osnovnih šol (MOST-VO), ki je zasnovan kot orodje za učitelja.

Točka osveščanja o varni rabi interneta Safe.si je del Centra za varnejši internet in je že vrsto let najpomembnejši deležnik na področju varne rabe interneta, kamor sodi tudi problematika spletnega nasilja. Preko sodelovanja s kolegi iz drugih evropskih držav, v okviru omrežja Insafe, je tudi korak pred vsemi drugimi manjšimi deležniki, saj lahko zazna nove trende in uspešnost pristopov pri odzivanju nanje, še preden se pojavijo $v$ našem okolju. Hkrati pa s svojim izkušnjami prispeva v bazo znanja celotne Insafe skupnosti. Redno pripravlja širok nabor gradiv, ki so v pomoč pri obravnavanju varne rabe interneta in spletnega nasilja ter svoje znanje in izkušnje posreduje vsem, ki to želijo ali potrebujejo. Safe.si organizira in izvaja predavanja ter delavnice za učence in dijake ter starše in pedagoške delavce, letno jih izvede približno tisoč. Vsako leto ob dnevu varne rabe interneta in ves mesec februar pripravlja aktivnosti, $v$ katere se I38 
šole množično vključujejo; aktivnosti so vsako leto drugačne in namenjene različnim ciljnim skupinam. V letu 2019 je bila ena izmed osrednjih aktivnosti spletna oddaja za starše, ki je dosegla izredno dobro gledanost že v živem prenosu in še boljšo kasneje, $\mathrm{v}$ prvi polovici leta preko 5200 ogledov, med njimi veliko skupinskih. Organizirale so jih šole v okviru roditeljskih sestankov.

Safe.si izdaja tudi gradiva $\mathrm{z}$ namenom preprečevanja oziroma učinkovite obravnave spletnih incidentov, $v$ katere so vpleteni učenci, zaposleni in starši. Primer je priročnik za vodstva šol Problematika spletne varnosti - smernice za vodstva šol, ki šolam nudi podporo in pomoč pri boljšem razumevanju različnih oblik spletnega nasilja ter svetuje pri ustreznem ravnanju.

Safe.si je le del projekta z imenom Center za varnejši internet, ki ga izvajajo Fakulteta za družbene vede Univerze v Ljubljani, Zavod Arnes, Zveza prijateljev mladine Slovenije in Zavod MISSS (Mladinsko informativno svetovalno središče Slovenije), financirata pa ga Agencija INEA (Innovation And Networks Executive Agency) pri Evropski komisiji in Ministrstvo za javno upravo.

- Center za varnejši internet združuje tri glavne segmente. Safe.si je točka osveščanja o varni rabi interneta in novih tehnologijah, namenjena osveščanju ciljnih skupin otrok, najstnikov, staršev, učiteljev in socialnih delavcev preko različnih spletnih in drugih aktivnosti, izobraževanj, delavnic, gradiv, promocijskih, medijskih kampanj o tem, kako varno in odgovorno uporabljati internet ter mobilne naprave.

- Tom telefon je svetovalna linija za težave na spletu. Svetovalci odgovarjajo na vprašanja otrok, mladih in njihovih staršev, o uporabi interneta. Tom ima tudi spletno klepetalnico, kjer lahko otroci, mladostniki in starši nasvete in pomoč dobijo v spletni obliki.

- Spletno oko omogoča anonimno spletno prijavo nezakonitih spletnih vsebin, kot so posnetki spolne zlorabe otrok (otroška pornografija) in sovražni govor.

Do konca leta 2019 se izvaja tudi izredno pomemben dvoletni projekt Odklikni! o nasilju nad ženskami in dekleti. Projektni partnerji so Ministrstvo za delo, družino in socialne zadeve, Fakulteta za družbene vede Univerze v Ljubljani, Ministrstvo za notranje zadeve - Policija ter Ministrstvo za pravosodje - Center za izobraževanje v pravosodju. Projekt zbira informacije o problematiki spletnega nasilja nad ženskami in izvaja medijske kampanje, pripravlja priročnike in izobraževalna gradiva, izobraževanja in delavnice za različne ciljne skupine. 
V okviru projekta je bila v lanskem letu izvedena tudi poglobljena raziskava o »virtualnem « nasilju med učenci in dijaki, ki je zapolnila raziskovalno praznino na tem področju, saj tovrstnih empiričnih raziskav pri nas kronično primanjkuje.

Projekt »Odklikni nasilje nad ženskami in dekleti« želi sprožiti spreminjanje odnosa do spletnega nasilja in nadlegovanja žensk in deklet ter seznaniti mlade, starše, potencialne žrtve in izvajalce nasilja o pojavnih oblikah in posledicah spletnega nasilja. Namen ima prispevati k širjenju strokovnega znanja za zagotovitev ustreznega sistema preprečevanja, preganjanja in zaščite pred spletnim nasiljem in nadlegovanjem žensk in deklet. Iz doslej zbranih podatkov že vemo, da so dekleta in ženske nasilju na spletu izpostavljene pogosteje kakor fantje in moški, doživljajo hujše oblike in težje posledice.

\section{Kaj lahko kot posamezniki in kot družba naredimo za preprečevanje $\gg v i r t u a l n e g a \ll$ nasilja}

Internet in nove tehnologije so nekaj, čemur se ne moremo izogniti, če otroka ne želimo izolirati iz družbe. V prispevku smo se osredotočili na nekatere možne težave, ki jih prinese uporaba interneta, a to ne pomeni, da smo pri tem nemočni. Za večino otrok pomeni uporaba tehnologij predvsem pozitivno izkušnjo, celo za tiste, ki so se že kdaj srečali s težavami. Večino težav je možno tudi preprečiti z osveščanjem otrok, mladostnikov in odraslih.

Naloga nas odraslih, ki prihajamo v stik z mladimi preko svoje profesionalne aktivnosti ali kot starši, je, da se zavedamo svoje vloge in se dovolj izobrazimo, da otrokom pri srečevanju s tehnologijami nudimo pomoč in ne izgovore za lastno nevednost (npr. »Saj itak več vedo kot jaz, tukaj jim res ne morem pomagati.«). Internet je realni svet $\gg z$ drugimi sredstvi« in naša dolžnost do mladih je, da se poučimo o tistih majhnih razlikah, ki ga ločijo od fizičnega sveta. Oboroženi s tem znanjem lahko otrokom nudimo oporo, ki jo potrebujejo, tudi ko zaidejo v težave.

Velik del vrstniškega nasilja se je preselil na splet. Nadlegovalci na tak ali drugačen način uporabljajo nove tehnologije za izvajanje nasilja, ki ostane odraslim večinoma nevidno. Nasilnež žrtvi pogosto grozi, da bo njeno življenje še veliko težje, če si drzne nasilje razkriti. Čeprav tehnologije ne poznamo dobro, se lahko zavedamo, da storilcu sicer olajša nasilno početje, ki pa ni občutno drugačno, kot je običajno fizično nadlegovanje. Če nasilnež žrtev pričaka za vogalom in jo prisili, da mu da denar ali kaj drugega, jo ponižuje in ji grozi, se to nikjer ne vidi. Podobno je pri spletnem nasilju, kjer ni nobenih modric, ki bi nam dale vedeti, da se nekdo znaša nad otrokom. V spletnem svetu je žrtev nekoliko lažje »počakati 
za vogalom «, a tudi pred tem se lahko branimo. Storilca lahko na različne načine blokiramo na medijih, ki jih uporablja, da mu »vogali« niso več tako zlahka dostopni.

Velika razširjenost »virtualnega « nasilja bi bila lahko tudi izhodišče za širši družbeni razmislek. $Z$ neodzivnostjo do virtualnega nasilja smo mnogim otrokom odvzeli občutek, da obstaja avtoriteta, ki jim lahko pomaga, če postanejo žrtve nadlegovanja. Ne zaupajo, da jim lahko nekdo stoji ob strani in jim pomaga, da se postavijo zase. V svojem spletnem (»on-line «) življenju imajo občutek, da so na nekakšnem »divjem zahodu «, kjer velja le pravica nasilja in moči. Seveda ne potrebujemo »šerifov«, pač pa lastno samozavest, da pristopimo k otroku in mu rečemo: »Lahko mi poveš, če se ti kaj neprijetnega dogaja na spletu, in jaz ti bom znal pri tem pomagati.« Bistvena je odločnost, da obljubo držimo tudi takrat, ko se moramo šele poučiti, kako se pomoči sploh lotiti.

Predvsem pa se moramo zavedati, da je podlaga interneta sicer res tehnologija, a ustvarjalci vsebin in uporabniki interneta smo mi, ljudje. $\mathrm{Ne}$ obstajajo tehnološke rešitve, ki bi preprečile in reševale zlorabe - mi smo tisti, ki moramo ukrepati.

\section{Literatura}

Livingstone S., Haddon L., Görzig A., in Olafsson K. (2011) Risks and safety on the internet: The perspective of European children. Fill Finfings. LSE, London: EU Kids Online.

Amy B. Jordan, Daniel Romer (2014) Media and the Well-Being of Children and Adolescents. Oxford: Oxford University Press.

Center za varnejši internet (2018) Končno poročilo 2016-20I8. https://safe. si/sites/default/files/koncno_porocilo_2016___2018.pdf

Cook, T. (2019) Cyberbullying facts and statistics for 2016-2019. https:// www.comparitech.com/internet-providers/cyberbullying-statistics/

Spletni vir A: http://www.netfamilynews.org/only-rarely-is-cyberbullying-sole-factor-in-teen-suicide-study (dostop 15.4.2019)

Spletni vir B: https://blogs.lse.ac.uk/parenting4digitalfuture/20I8/o8/or /a-clearer-picture-of-what-hurts-kids-online/

Spletni vir C: http://safe.si/novice/kako-se-odzvati-na-spletno-ustrahovanje (dostop 15.4.2019)

Spletni vir D: https://www.arnes.si/izobrazevanje/ (dostop 15.4.2019)

Spletni vir E: http://odklikni.enakostspolov.si/o-projektu/ (dostop 15.4 .2019 ) 
Spletni vir F: https://safe.si/safesi-videi/pogovor-za-starse-vzgoja-za-internet (dostop 15.4.2019)

Spletni vir G: https://www.sciencedaily.com/releases/2018/04/1804 I9130923.htm

Spletni vir H: https://cyberbullying.org/bullying-cyberbullying-suicideamong-us-youth

Spletni vir I: https://psychcentral.com/lib/cyberbullying-and-teen-suicide/

Spletni vir J: https://www.healthyplace.com/suicide/ bullying-cyberbullying-and-teen-suicide

DOI: https://www.doi.org/10.32320/1581-6044.30(3-4)131-1 42 